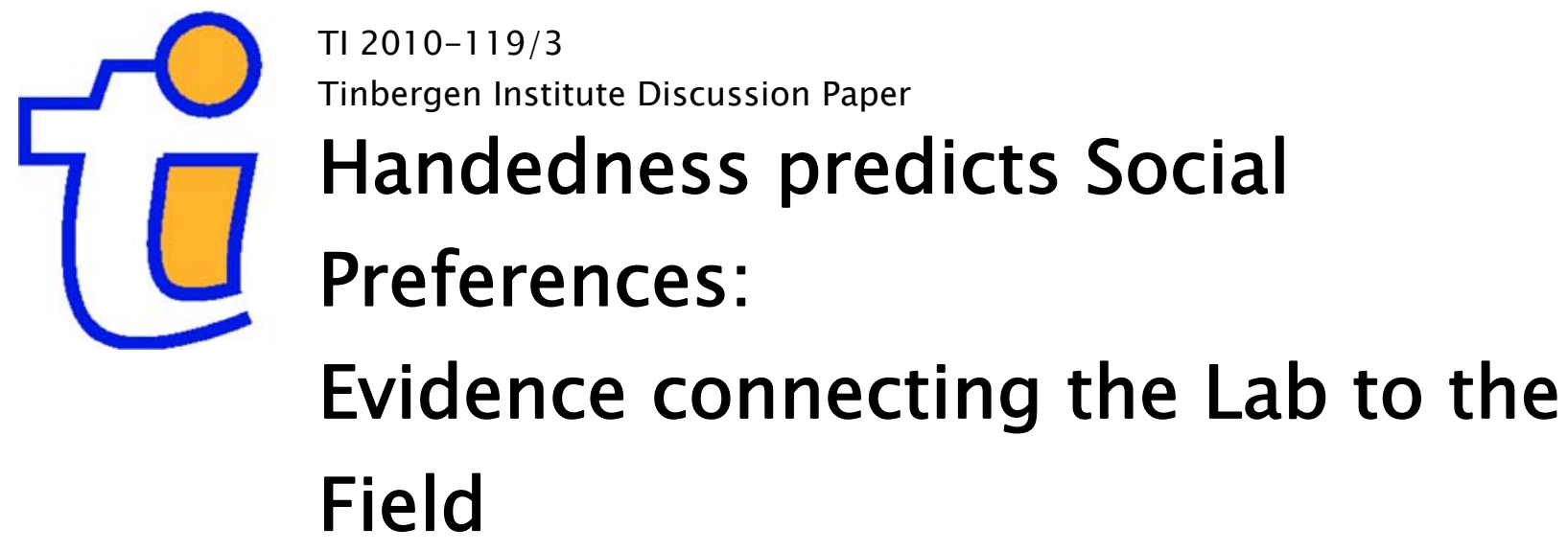

Thomas Buser

University of Amsterdam, and Tinbergen Institute. 


\section{Tinbergen Institute}

The Tinbergen Institute is the institute for economic research of the Erasmus Universiteit Rotterdam, Universiteit van Amsterdam, and Vrije Universiteit Amsterdam.

Tinbergen Institute Amsterdam

Roetersstraat 31

1018 WB Amsterdam

The Netherlands

Tel.: +31(0)205513500

Fax: $+31(0) 205513555$

Tinbergen Institute Rotterdam

Burg. Oudlaan 50

3062 PA Rotterdam

The Netherlands

Tel.: + $31(0) 104088900$

Fax: $+31(0) 104089031$

Most TI discussion papers can be downloaded at http://www.tinbergen.nl. 


\title{
Handedness Predicts Social Preferences: Evidence Connecting the Lab to the Field
}

\author{
Thomas Buser*
}

November 2010

\begin{abstract}
It is now generally accepted that some people are more altruistic, more trusting, or more reciprocal than others, but it is still unclear whether these differences are innate or a consequence of nurture. We analyse the correlation between handedness and social preferences in the lab and find that lefthanded men are significantly more generous when recipients have the possibility to reciprocate and exhibit stronger positive reciprocity themselves. Left-handed women are significantly less altruistic. We test the external validity of these findings by connecting them to large-scale survey data from the Netherlands and the US covering altruistic behaviour and reciprocity outside the lab. The results largely carry over. We argue that our findings demonstrate that social preferences are at least partially determined by nature and help to shed light on their neural origins.
\end{abstract}

\footnotetext{
${ }^{*}$ University of Amsterdam, School of Economics (t.buser@uva.nl). I am indebted to Hessel Oosterbeek and Erik Plug for their advice and invaluable support. I gratefully acknowledge financial support from the University of Amsterdam through the Speerpunt Behavioural Economics and thank CREED for letting me use their lab. This paper draws on data of the LISS panel of CentERdata.
} 


\section{Introduction}

It is widely known that some people are more altruistic, more trusting, or more reciprocal than others. However, we know little about the determinants of these individual differences. In this paper we explore the extent to which differences in social preferences are of biological origin. In particular, we analyse the correlation between social preferences and handedness, which is strongly related to important and well-studied neurological differences. We argue that a significant correlation between handedness and economic choices in social situations would indicate that nature plays an important role in shaping social preferences.

In a first step, we estimate the correlation between handedness and choices in a range of social preference games in the laboratory. We also gathered information on handedness from the respondents of a Dutch Internet panel which allows us to link our lab results on handedness to survey data on altruistic behaviour in the field and attitude questions concerning trust and reciprocity. This survey data allows us to test the external validity of our lab findings both by investigating whether they apply to a diverse and representative non-student population and by connecting them to behaviour outside the lab. We also use US survey data to further replicate our findings.

Left-handedness is associated with important differences in brain development. It is, for example, a well-established fact that while language ability is controlled by the left side (hemisphere) of the brain in 97 percent of right-handers, it is bilateral or controlled by the right side in more than 30 percent of left-handers (Knecht et al., 2000). The brains of left-handers are found to exhibit lower rates of brain hemisphere specialisation in general, meaning that left-handers more commonly use both sides of the brain for a given task. ${ }^{1}$ The main connection between the two hemispheres of the brain is a thick band called corpus callosum which contains millions of nerves and acts as a data-wire that allows the two hemispheres to "speak" to each other. Left-handers have a thicker corpus callosum, which results in an increased capacity for communication between the two hemispheres and implies that the brains of left-handers are better integrated in processing information (Witelson, 1985). ${ }^{2}$ Left-handers therefore perform better at activities that require rapid transfer of information, such as communication and empathising (Hines et al., 1992). ${ }^{3}$ It is important for our purposes to note that the correlation between handedness and the size of the corpus callosum is much stronger in males than in females (Witelson and Goldsmith, 1991; Grimshaw et al., 1995). This strand of the literature indicates potentially higher levels of empathy in left-handers, especially for males.

Handedness has also been associated with natural prenatal exposure to testosterone which is itself thought to have a strong impact on brain development. Prenatal testosterone exposure is thought

\footnotetext{
${ }^{1}$ See Coren (1993) for an accessible survey of the research on handedness.

${ }^{2}$ Indeed, it has been hypothesised that handedness arises from differences in the size of the corpus callosum (Witelson, 1985).

${ }^{3}$ Also see Baron-Cohen (2003) and the references therein.
} 
to shift brain development away from a brain geared towards empathy in direction of a brain wired for dealing with systems. It is also a potential cause of autism, a condition associated with very low levels of empathy. ${ }^{4}$ Prenatal exposure to testosterone has a negative impact on the size of the corpus callosum (Witelson, 1991) and may therefore shift handedness towards the right (Witelson and Nowakowski, 1991). This effect is probably exclusive to men for whom the link between handedness and the size of the corpus callosum is much stronger and who are exposed to much higher levels of prenatal testosterone exposure. ${ }^{5}$ The opposite relation (prenatal testosterone being a cause of lefthandedness) has also been hypothesised (Geschwind and Galaburda, 1987). The empirical evidence is inconclusive, with some evidence found in both directions. ${ }^{6}$ In summary, the strength of prenatal exposure to testosterone, which is associated with lower levels of empathy, may be both positively or negatively correlated with left-handedness. A negative correlation, implying higher levels of empathy in left-handers, is more likely for men.

The psychological literature has found left-handers to be different from right-handers along many dimensions. More often than not, the effects are stronger in males and it is common to even find opposite effects of handedness for women. Coren (1995), for instance, finds creativity (specifically "divergent thinking") to be positively correlated with left-handedness in men only. Goldberg et al. (1994) find that left-handedness is associated with novelty-seeking, again particularly in males. Looking at several measures of school performance and leadership skills, Faurie et al. (2006) find a positive association with left-handedness for boys but a negative one for girls and Sanders et al. (1982) find the same pattern for spatial ability.

In economics, left-handedness has been associated with higher wages for men but lower wages for women (Denny and O'Sullivan, 2007), higher wages amongst college-educated men (Ruebeck et al., 2007), and worse average outcomes in a range of early childhood development indicators (Johnston et al., 2007). Given that brain differences associated with handedness differ between the sexes (and are stronger in men) and given the findings of the psychological literature, it comes as no surprise that economic studies also find gender differences in the effects of handedness.

We expect higher levels of empathy to lead to higher levels of trusting and altruism. From the literature on the link between handedness and the size of the corpus callosum in males we therefore derive the hypothesis that left-handed men, but not women, give more in all social preference games. While higher levels of hemisphere integration should also lead individuals to be more acutely aware of others' reciprocity and better at inferring their reactions, it is not straightforward to predict the direction of the correlation between handedness and reciprocity itself. Again, we would expect any

\footnotetext{
${ }^{4}$ See Baron-Cohen et al. (2004) for a review of the large body of research backing the testosterone-empathy link and Baron-Cohen (2003) for a more accessible account. Manning et al. (2001) find a strong correlation between physical markers for prenatal testosterone exposure and autism.

${ }^{5}$ See Grimshaw et al. (1995) for a summary of the various theories (and supporting empirical evidence) linking prenatal testosterone exposure to handedness.

${ }^{6}$ See for example Manning and Peters (2009).
} 
effect of handedness on reciprocity to be present primarily in males. The findings of the literature on the link between left-handedness and prenatal testosterone exposure are less clear-cut. We interpret them as being ambiguous with respect to the direction of the correlation between left-handedness and altruism for men while rather predicting a negative correlation for women.

A number of previous papers have investigated the link between nature and social preferences in the lab. A series of placebo controlled studies demonstrates that the hormone oxytocin leads to higher offers in the trust game (Kosfeld et al., 2005; Baumgartner et al., 2008) and increases generosity in the ultimatum game (Zak et al., 2007). Burnham (2007) finds that higher testosterone levels are associated with a higher probability of rejection in the ultimatum game and Zak et al. (2009), in a placebo controlled study, find testosterone to cause both lower offers and more rejections. Zethraeus et al. (2009), on the other hand, find no impact of testosterone and oestrogen levels on altruism, trust, or fairness. A series of studies finds that physical markers for the strength of prenatal testosterone exposure are significantly correlated with rejection rates in the ultimatum game (van den Bergh and Dewitte, 2006), contributions in the public good game (Millet and Dewitte, 2006), and offers in the dictator game (Millet and Dewitte, 2009). Comparing the behaviour of monozygotic and dizygotic twins, a number of studies demonstrate that giving and reciprocity in the trust game (Cesarini et al., 2008), responder behaviour in the ultimatum game (Wallace et al., 2007), and generosity in the dictator game (Cesarini et al., 2009) are partly hereditary. Yet another strand of the literature has found links between individual genes and behaviour in the dictator game (Knafo et al., 2008; Israel et al., 2009). ${ }^{7}$

We let a sample of 252 subjects participate in a series of social preference games including the standard dictator, ultimatum, public good, and trust games. We also used a post-experimental questionnaire to collect information on handedness and other demographic variables. We test the external validity of our results by gathering handedness information from 5823 respondents of a representative Dutch Internet panel ${ }^{8}$ and linking it to survey data measuring altruistic behaviour and attitudes towards reciprocity outside of the lab. We also use US data from the National Longitudinal Survey

\footnotetext{
${ }^{7}$ Cross-country comparisons of choices in economic experiments show that culture also matters. In a meta-analysis of ultimatum bargaining experiments, Oosterbeek et al. (2004) find differences in the behaviour of responders (but not of proposers) across geographical regions whereas some studies, including Roth et al. (1991), find significant variation across countries for both behaviours. Henrich et al. (2001) conduct ultimatum, public good, and dictator games with 15 small scale societies and find substantial variation for all choices. Herrmann et al. (2008) study contribution rates and punishment behaviour in public good games across 16 societies and find large and significant variation. In a follow-up grouping countries into six world cultures, the authors show that cultural background has a substantial impact (Gächter et al., 2010). There are also a few trust game studies with multi-national subject pools. Using subjects from four different countries, Buchan et al. (2002) show that nationality explains a significant part of the variance in both giving and reciprocating behaviour. Ashraf et al. (2006) find that subjects from Russia, South Africa, and the United States give similar amounts but that Russians return a higher percentage. Holm and Danielson (2005) find that Swedish and Tanzanian subjects send and return very similar proportions but that the correlation between the amount received and the amount returned is significant and positive only for Swedish subjects.

${ }^{8}$ The LISS panel: www.lissdata.nl.
} 
of Youth (NLSY) ${ }^{9}$, which contains both handedness information and some indicators of altruism, to further confirm our results.

The rest of the paper is organised as follows. Section 2 gives details on the experimental design and the laboratory data and describes the lab experiment results. Section 3 describes the survey data. Section 4 contains the results obtained using the survey data and Section 5 concludes.

\section{Laboratory experiment}

\subsection{Design and sample}

The experimental design consists of a range of standard social preference games which have been widely used in the literature: a trust game, an ultimatum game, a public good game, and a dictator game. Overall, the experiment lasted for seven rounds and subjects were randomly and anonymously re-matched in each round. One of the rounds was randomly picked for payment at the end of the experiment. Subjects also received a show-up fee of $€ 10$. We ran a total of twelve sessions in December 2009 and January 2010, all of which were conducted in the computer laboratory of the Center for Research in Experimental Economics and Political Decision-Making (CREED) at the University of Amsterdam. The experiment was programmed and conducted with the software z-Tree (Fischbacher, 2007). The sessions lasted for approximately two hours and average earnings were around $€ 21$.

In the trust game (Berg et al., 1995), two subjects are paired up and each receives an endowment of $€ 10$. The first mover (the "Proposer") can then decide how much of his endowment he wishes to send to the second mover (the "Responder"). The amount sent is tripled and the Responder can then decide how much of the money, including his endowment, to send back to the Proposer. Because the Responder has no financial incentive to send back anything, the Nash equilibrium predicts that the Proposer will not send any money. In the social optimum, on the other hand, the Proposer would send his entire endowment of $€ 10$ and the Responder would return less than $€ 30$ and more than $€ 10$, leaving both parties better off. There is a large literature showing that Proposers send on average around 50 percent of their endowment and that Responders reciprocate by returning on average nearly 50 percent of the received transfer (Levitt and List, 2007). In our experiment, we implemented two rounds of the trust game with each subject taking each role once.

In the ultimatum game (Güth et al., 1982), the Proposer receives an endowment of $€ 20$ while the Responder starts out with nothing. The Proposer decides how much to send to the Responder who can then decide whether to accept or reject the proposal. In case of rejection, both players receive zero, so that the Nash equilibrium predicts that all positive offers are accepted and Proposers should thus send

\footnotetext{
${ }^{9}$ http://www.nlsinfo.org/
} 
Table 1: Lab sample characteristics

\begin{tabular}{lcccc}
\hline & Sample & Women & Men & Gender-dif. P-val. \\
\hline $\mathrm{N}$ & 252 & 157 & 95 & \\
Left-handed & 20 & 11 & 9 & 0.485 \\
Age & 22.1 & 22.0 & 22.3 & 0.663 \\
Dutch & $72 \%$ & $69 \%$ & $77 \%$ & 0.169 \\
\hline
\end{tabular}

Gender-difference P-values are from Wilcoxon rank-sum tests

the lowest possible amount. Again, there is a large literature showing that Proposers send positive amounts, usually in the range between 25 and 50 percent of their endowment, and that Responders are willing to forfeit money by rejecting low offers (Roth, 1995). Again, there were two rounds with each subject fulfilling each role once.

The public good game is a generalisation of the prisoner's dilemma game whereby subjects are matched in groups of four and are each endowed with $€ 15$. They can then decide how much of the endowment to keep and how much to give to the group. Each Euro given to the group is doubled and split equally amongst the group members such that each Euro given to the group pays 50 Cents to each group member. Obviously, the social optimum is for all the players to invest everything, but as each player has an incentive to free-ride, the Nash equilibrium predicts zero contributions. There is a large literature reporting substantial positive contributions, usually around 50 percent of the initial endowment in a one-shot setting (Ledyard, 1995).

Finally, we implemented a binary version of the dictator game (Kahneman et al., 1986). In the dictator game, the Proposer again receives an endowment of $€ 20$ and has to pick between two options: splitting the pot equally with the Responder (who receives no endowment) or keeping $€ 18$ while giving only $€ 2$ to the Responder. The Responder has no possibility to reciprocate and the game is consequently a good tool for measuring altruism. The Nash equilibrium of course predicts that the Proposer sends the smallest amount possible, but a large literature finds that when able to decide freely, over 60 percent of subjects send a positive amount (Roth, 1995).

The laboratory sample consists of 252 undergraduate students, 157 of whom are female. In addition to participating in the experiment, the subjects also filled out a questionnaire asking whether they are left- or right-handed. We also collected additional demographic information including gender, age and nationality. The questionnaire responses are summarised in Table 1. The proportion of left-handers does not vary significantly between the genders but this is likely due to the small sample size as the literature on handedness reports a higher prevalence of left-handedness amongst men (Coren, 1993). Indeed we find that in our sample $9.5 \%$ of the men but only $7.0 \%$ of the women are left-handed. 


\subsection{Results}

Table 2 contains regression results analysing the effect of handedness on choices in the social preference games. Column 1 shows the results for the initial offer in the trust game while Column 2 refers to the proportion returned by the Responders (including their initial endowment). Columns 3 and 4 respectively contain the regression results for giving and rejecting in the ultimatum game. Columns 5 and 6 refer to choices in the public good game, with Column 5 containing the results for the allocation and Column 6 for a binary variable indicating whether a subject chose to make a positive allocation. Finally, Column 7 refers to the choice of the selfish allocation in the dictator game. Demographic controls consist of age, gender, and nationality. The regressions in Columns 2 and 4, which deal with responder behaviour, also control for the amount of money received from the Proposer. ${ }^{10}$

Behaviour in the social preference games is largely within the range of choices observed in the previous literature which typically finds average giving rates of between $25-50 \%$ for the ultimatum game and roughly $50 \%$ for the trust game. The responders in our trust game are themselves endowed with $€ 10$ and the proportion returned is calculated with respect to the sum of the received transfer and this initial endowment. Even taking this into account, the proportion sent back is somewhat below the average finding of roughly 50\% returned (responders send back an amount leaving the proposer weakly better off only $55 \%$ of the time). Responder behaviour in the ultimatum game is also in line with the literature with most rejections occurring for offers of $25 \%$ of the endowment or below. The public good contributions amount to $42 \%$ of the endowment and are therefore not far from the average finding of roughly $50 \%$ for one-shot games. Finally, the low proportion of equal allocations in our binary dictator game is also in line with the literature as offers of $50 \%$ of the endowment are a relatively rare occurrence.

When we compare the behaviour of left- and right-handed subjects for the whole sample, not all that many effects are apparent: left-handers give significantly more in the trust game and are less likely to reject an offer in the ultimatum game. Striking differences appear, however, when we split the sample by gender. Amongst male subjects, the left-handers make offers in the trust and ultimatum games which are both statistically and economically significantly higher. They also return a larger proportion in the trust game and are less likely to reject offers in the ultimatum game. Female lefthanders show none of these effects but are significantly less likely than other female subjects to choose the generous allocation in the dictator game. At first glance, these results are in accordance with our hypothesis of a positive impact of left-handedness on giving rates for men and a potential negative impact for women.

We first take a closer look at giving behaviour. Were it not for the results of the public good and dictator games, where the choices of left-handed men are statistically indistinguishable from those of

\footnotetext{
${ }^{10}$ We do not report regression results without demographic controls in this section as excluding them does not affect qualitative results or significance in any of the regressions.
} 
Table 2: Handedness and social preferences

$\begin{array}{llllll}1 & (2) & (3) & \text { (4) } & \text { (5) }\end{array}$

Trust Proportion Ultimatum Rejection Public Good PG Positive Selfish

Whole sample:

$\begin{array}{lccccccc}\text { Left-handed } & 2.118 * * * & 0.027 & 0.820 & -0.074 * & 0.151 & -0.010 & 0.071 \\ & (0.663) & (0.025) & (0.784) & (0.044) & (1.211) & (0.098) & (0.056) \\ \mathrm{N} & 252 & 252 & 252 & 252 & 252 & 252 & 252 \\ \text { Mean } & 4.020 & 0.121 & 7.992 & 0.127 & 6.242 & 0.774 & 0.881 \\ \mathrm{SD} & (3.076) & (0.141) & (3.180) & (0.334) & (4.825) & (0.419) & (0.325)\end{array}$

Men:

$\begin{array}{lccccccc}\text { Left-handed } & 3.260 * * * & 0.063 * & 2.199 * & -0.104 * * & -0.0267 & 0.093 & 0.003 \\ & (0.911) & (0.037) & (1.137) & (0.048) & (1.950) & (0.160) & (0.127) \\ \mathrm{N} & 95 & 95 & 95 & 95 & 95 & 95 & 95 \\ \text { Mean } & 4.453 & 0.106 & 7.758 & 0.095 & 5.853 & 0.663 & 0.895 \\ \text { SD } & (3.429) & (0.135) & (2.747) & (0.294) & (5.409) & (0.475) & (0.309)\end{array}$

Women:

Left-handed

$\begin{array}{ccccccc}1.193 & 0.006 & -0.140 & -0.030 & 0.187 & -0.109 & 0.109 * * \\ (0.903) & (0.039) & (0.997) & (0.062) & (1.513) & (0.121) & (0.042) \\ 157 & 157 & 157 & 157 & 157 & 157 & 157 \\ 3.758 & 0.130 & 8.134 & 0.147 & 6.478 & 0.841 & 0.873 \\ (2.820) & (0.145) & (3.416) & (0.355) & (4.437) & (0.367) & (0.335)\end{array}$

\begin{tabular}{lccccccc}
\hline Controls & yes & yes & yes & yes & yes & yes & yes \\
Offer received & no & yes & no & yes & no & no & no \\
Scale & $0-10$ & $0-1$ & $0-20$ & binary & $0-15$ & binary & binary \\
\hline
\end{tabular}

Robust standard errors in parentheses; *** $\mathrm{p}<0.01, * * \mathrm{p}<0.05, * \mathrm{p}<0.1$

Controls consist of age, nationality and gender 
the right-handers, the impression would be one of stronger altruism. Relative to their right-handed counterparts, the male left-handers make choices which leave their partners better off in both the trust and ultimatum games, which confirms our initial hypothesis. But it is important to note that this effect is only present in the games in which receivers can reciprocate which cannot be explained by a positive effect of handedness on altruism. A possible explanation is that left-handers have a stronger belief in the reciprocity and fairness of others. ${ }^{11}$ We will use our survey data to have a closer look at this hypothesis in Section 4.2.

In Table 3, we take a closer look at the link between handedness and reciprocity in the trust game. Here we regress the proportion returned in the trust game on a handedness dummy, the amount received from the proposer, and the interaction of these two variables. It becomes apparent that left-handed men do not return more money per se; actually, the coefficient on the handedness dummy is negative and insignificant. Rather, the proportion they return increases much more steeply with the amount received from their proposer. While right-handed men return around two percent more for each Euro they receive, left-handed men increment their reciprocity by over six percent for each Euro received. Given that we do not use the strategy method, the amount of rejections in the data is too small in order to conduct the same analysis for the ultimatum game. But in the light of these results, it seems plausible that for left-handed men the willingness to reject reduces faster with an increase in the transfer received and that this leads to the significantly lower likelihood of rejection. These results again indicate that the differences in behaviour between left-handed and right-handed men are not driven by differences in altruism (in that case the left-handers should return more whatever the amount received) but by a stronger willingness to reciprocate.

The female sample exhibits a strikingly different pattern. There are no significant differences in giving between right-handed and left-handed women in either the trust or the ultimatum game. The same is true for the proportion returned in the trust game and the likelihood of rejection in the ultimatum game. The regression results reported in Column 2 of Table 3 show that there are no differences in conditional reciprocity in the trust game either. On the other hand, left-handed women are significantly more likely to be selfish in the dictator game which is in accordance with the hypotheses drawn from the literature on the link between handedness and prenatal testosterone exposure. Given that the neurological differences associated with handedness differ between men and women, it comes as no surprise that the effects of handedness on social preferences vary between the genders.

This section presented results on handedness which strongly imply that individual differences in neural structures play an important role in shaping differences in social preferences. The observed effects of handedness are, for instance, stronger than most of the cultural differences or gender effects obser-

\footnotetext{
${ }^{11}$ Similarly, left-handed men might simply be better at inferring the reactions of others so that their higher giving rates translate into higher profits. This is not the case as ultimatum proposer profits are virtually the same for left-handed and right-handed males and trust proposer profits are (insignificantly) lower for left-handers. On the other hand, the ultimatum offers of left-handed men are 12.8 percent less likely to get rejected than those of right-handed men (OLS regression without additional controls; $\mathrm{p}=0.001$ ).
} 
Table 3: Handedness and reciprocity in the trust game

\begin{tabular}{lccc}
\hline & $(1)$ & $(2)$ & $(3)$ \\
& Proportion & Proportion & Proportion \\
\hline \multirow{2}{*}{ Offer received } & $0.025^{* * *}$ & Men: & Women: \\
& $(0.003)$ & $0.021^{* * *}$ & $0.028^{* * *}$ \\
Left-handed & 0.006 & $(0.006)$ & $(0.003)$ \\
& $(0.027)$ & -0.035 & -0.005 \\
Left-handed $x$ Offer received & 0.006 & $(0.029)$ & $(0.051)$ \\
& $(0.007)$ & $0.041 * * *$ & 0.002 \\
Controls & yes & $(0.009)$ & $(0.009)$ \\
$\mathrm{N}$ & 252 & yes & yes \\
\hline Robust standard errors in parentheses; $* * * \mathrm{p}<0.01, * * \mathrm{p}<0.05, * \mathrm{p}<0.1$ & & 157 \\
Controls consist of age, nationality and gender & & &
\end{tabular}

ved in the previous literature. ${ }^{12}$ As hypothesised, left-handedness has a positive effect on giving rates and affects reciprocity in men only. Contrary to our hypotheses however, the higher giving rates for male left-handers are not a consequence of increased altruism but rather seem to originate in a stronger belief in the reciprocity of others. The gender differences in the effects of handedness are striking but in accordance with the evidence on the neural correlates of handedness and the psychological literature, which often finds the effects of handedness to differ between the sexes. In the following sections, we will investigate whether these links between handedness and social preferences as measured by standard games are present in altruistic and reciprocal behaviour outside of the lab as well.

\section{Survey data}

An often voiced concern about laboratory experiments measuring social preferences is that their findings might not be externally valid. Levitt and List (2007) identify a range of potential problems with generalising the results of lab experiments on social preferences including the effect of scrutiny by the experimenter in the lab, lack of anonymity between the subject and the experimenter, the fact that subtle (and potentially inadvertent) manipulations of context can have large effects on behaviour, low stakes compared to decisions outside the lab, and subject self-selection into the experiment. Some of these concerns apply mostly to experiments designed to observe a certain behaviour (say, positive giving in the dictator game) from which general behaviour is inferred (people are altruistic) and less to our experiment which features a within design comparing with each other the choices made by different groups.

\footnotetext{
${ }^{12}$ For cultural differences in social preferences refer to the literature reviewed above. For a review of gender differences in social preferences see Croson and Gneezy (2009).
} 
Table 4: LISS sample characteristics

\begin{tabular}{lcccc}
\hline & Sample & Men & Women & Gender-dif. P-val. \\
\hline $\mathrm{N}$ & 4074 & 1851 & 2346 & \\
Left-handed & 477 & 247 & 241 & 0.001 \\
Age & 39.9 & 40.1 & 39.8 & 0.439 \\
Monthly income $(€)$ & 1360 & 1943 & 902 & 0.000 \\
Education level & 3.56 & 3.60 & 3.52 & 0.123 \\
\end{tabular}

Gender-difference P-values are from Wilcoxon rank-sum tests

Two important remaining concerns are that the undergraduate student subjects we use in our laboratory experiment might be somehow different from the rest of the population and that people might behave differently in the lab than they would in other contexts. We will address these concerns using survey data on altruism and reciprocity outside of the lab covering a large and diverse population. The aim is to see whether the effects observed in the lab carry over to some of the behaviours the social preference games are intended to predict and to show that they apply to a diverse and international population.

We collected handedness data from responders to the LISS panel, an ongoing Internet panel covering 5000 households comprising 8000 individuals which were selected to be representative of the Dutch population. The participating individuals have already responded to a large number of questionnaires, some of which contain measures of altruism and reciprocity. We asked them whether they are lefthanded or right-handed but did not gather any additional information and our analysis therefore makes use of measures that are contained in the existing LISS datasets. In total, 5823 responders answered our questions. A potential worry with this more diverse sample is that amongst the older responders there might be a large number of left-handers who were forced to switch to using their right hand by their parents or teachers, a practice that was very common in the past (Coren, 1993). For this reason, we exclude subjects of sixty years or older from our sample which leaves us with a sample size of $4074 .{ }^{13}$ The descriptive statistics for this sample can be found in Table 4. The proportion of left-handers is in line with rates of left-handedness found in the general population (Coren, 1993). Also, as expected, men are significantly more likely to be left-handed than are women.

The data available on (varying subsamples of) the panel members span dozens of questionnaires containing thousands of variables. Apart from the data we collected, we will limit ourselves to two

\footnotetext{
${ }^{13}$ We also asked responders how strong their preference for left or right was on a scale from 1 - not so strong - to 5 - very strong - and indeed we find that subjects who are sixty years of age or older are much more likely to indicate a weak preference for their hand of choice (Wilcoxon rank-sum test: $\mathrm{p}<<0.01$ ). This phenomenon is much more significant in right-handers $(\mathrm{p}<<0.01)$ than in left-handers $(\mathrm{p}=0.24)$, indicating that amongst the older subjects there are many individuals whose preference for right is a weak one. Also, there is no significant relationship between mixed-handedness (defined as indicating a preference strength of 3 or lower) and age for subjects under sixty years of age (OLS regression yields a p-value of 0.34) while this relationship is highly significant for subjects of sixty years or older $(\mathrm{p}<0.01)$.
} 
Table 5: NLSY sample characteristics

\begin{tabular}{lcccc}
\hline & Sample & Men & Women & Gender-dif. P-val. \\
\hline $\mathrm{N}$ & 7673 & 3862 & 3811 & \\
Left-handed & 923 & 521 & 402 & 0.000 \\
Age & 24.9 & 24.9 & 25.0 & 0.155 \\
Yearly income (US\$) & 20412 & 23528 & 17125 & 0.000 \\
Non-white & 3744 & 1851 & 1893 & 0.127 \\
& & & & \\
\hline
\end{tabular}

Gender-difference P-values are from Wilcoxon rank-sum tests

questionnaires containing measures that are directly relevant to our research. The first study we use is the most recent wave of the "Social Integration and Leisure" module of the LISS core study. This questionnaire contains data on altruistic behaviour such as donating money to a range of charitable organisations, doing volunteer work, and performing informal care for another person. The second study we use is the "European Social Survey" module which contains attitude questions concerning trust and reciprocity. ${ }^{14}$

The 1997 wave of the National Longitudinal Survey of Youth (NLSY) ${ }^{15}$, a US panel survey covering a nationally representative sample of individuals who were 12 to 16 years old at the end of 1996, also contains information on both handedness and a limited number of indicators of altruism. The 2007 questionnaire contains binary indicators for donating money and doing volunteer work which are also available on the LISS panel so that we can further check the external validity of our findings by investigating whether they apply to the US population. Table 5 contains descriptives of the NLSY sample. All the subjects were born between 1980 and 1984 and age-related issues do therefore not come into play. ${ }^{16}$

\section{Survey results}

\subsection{Survey measures of altruistic behaviour}

While it is hard to imagine what would constitute a straightforward survey measure reciprocal behaviour outside the lab, altruism is easier to measure and both the LISS and NLSY data do contain some straightforward measures of altruism. This section will thus concentrate on the analysis of the correlation between handedness and altruistic behaviour. Based on the experimental results from the

\footnotetext{
${ }^{14} \mathrm{~A}$ description of the two modules, the questionnaires, and the data can be found online at http://www.lissdata.nl/dataarchive/study_units/view/6 and at http://www.lissdata.nl/dataarchive/study_units/view/59.

${ }^{15} \mathrm{http}: / /$ www.bls.gov/nls/y97summary.htm

${ }^{16}$ The panel oversamples the black and hispanic populations which is not an issue since handedness does not vary with race $(\mathrm{p}=0.593$, Fisher's exact test).
} 
lab discussed above, we would expect left-handedness to have a negative impact on straightforward altruism especially in women.

The "Social Integration and Leisure" module of the LISS core study contains several measures of altruistic behaviour, namely binary indicators for donating money, doing voluntary work, and performing informal care for a sick relative or friend. Table 6 reports regression results for the impact of handedness on these behaviours. In addition to the control variables used in the previous section, we also include gross monthly income and education ${ }^{17}$ in the controls as these can be expected to have a strong impact especially on donations. ${ }^{18}$

The donation regressions in Table 6 confirm our lab results on altruism: left-handers as a whole are significantly less likely to donate money and this effect is completely attributable to women. After inclusion of controls, female left-handers are around 5.5 percentage points less likely to donate money, which is a sizeable reduction compared to an average proportion of donors of around 38 percent. The picture becomes less clear with the volunteering regressions though. Left-handers as a whole are not significantly less keen on doing volunteer work. But the effect is strongly and significantly negative for left-handed men - a reduction of 7.4 percentage points relative to an average propensity of 32 percent - while the coefficient is insignificant and positive for left-handed women. This gender difference is rather unexpected given the lab findings. Finally, left-handers are neither more nor less likely to perform informal care for others.

The LISS dataset also contains information on membership in charitable organisations. These fall into two categories: organisations for "humanitarian aid, human rights, minorities or migrants" and organisations for "environmental protection, peace or animal rights". Membership in such an organisation arguably indicates a preoccupation with the common good and thus an altruistic streak. We find that left-handers are less likely to be a member of a humanitarian organisation. This effect is present for both men and women separately too but is only significant at the 10-percent level for the sample as a whole (economically, at 1.8 percentage points the effect is relevant relative to a sample average of 4.9 percent). We do not observe this pattern for membership in environmental organisations, though, where left-handed women are actually 4.1 percentage more likely than average to be a member (but this effect is only significant at the 10-percent level and after the inclusion of controls).

Table 7 contains regression results for the NLSY sample. These results, based on a sample of American twenty-somethings, mostly confirm the results obtained from the Dutch LISS sample. Again, left-handed women are significantly less likely to have donated money while the effect for men is zero. The magnitude of the effect is 4.0 percentage points which is sizeable compared to a sample average of 21.8 percent. We also find that both men and women are around 3 percentage points less

\footnotetext{
${ }^{17}$ Education is divided into five categories according to the definition used by Statistics Netherlands.

${ }^{18}$ The "Social Integration and Leisure" module of the LISS core study asks respondents whether they donated money to or volunteered for a range of organisations including humanitarian, environmental, and social. Our binary indicators are composite measures which indicate that an individual has donated to or volunteered for at least one type of organisation.
} 
Table 6: Handedness and altruistic behaviour (LISS panel)
(1)
(2)
(3)
(4)
(5)
(6)
Donating money

\begin{tabular}{|c|c|c|c|c|c|c|}
\hline & Full Sample: & & Men: & & Women: & \\
\hline \multirow[t]{2}{*}{ Left-handed } & $-0.041 *$ & -0.029 & -0.007 & -0.000 & $-0.069 * *$ & $-0.055^{*}$ \\
\hline & $(0.024)$ & $(0.024)$ & $(0.035)$ & $(0.034)$ & $(0.034)$ & $(0.033)$ \\
\hline $\mathrm{N}$ & 3691 & 3691 & 1620 & 1620 & 2071 & 2071 \\
\hline Mean & 0.376 & 0.376 & 0.354 & 0.354 & 0.392 & 0.392 \\
\hline \multirow[t]{3}{*}{$\mathrm{SD}$} & 0.484 & 0.484 & 0.478 & 0.478 & 0.488 & 0.488 \\
\hline & \multicolumn{6}{|c|}{ Volunteering } \\
\hline & Full Sample: & & Men: & & Women: & \\
\hline \multirow[t]{2}{*}{ Left-handed } & -0.017 & -0.012 & $-0.076 * *$ & $-0.074 * *$ & 0.042 & 0.047 \\
\hline & $(0.024)$ & $(0.024)$ & $(0.032)$ & $(0.032)$ & $(0.035)$ & $(0.035)$ \\
\hline $\mathrm{N}$ & 3692 & 3692 & 1621 & 1621 & 2071 & 2071 \\
\hline Mean & 0.318 & 0.318 & 0.304 & 0.304 & 0.330 & 0.330 \\
\hline \multirow[t]{2}{*}{ SD } & 0.466 & 0.466 & 0.460 & 0.460 & 0.470 & 0.470 \\
\hline & \multicolumn{6}{|c|}{ Informal care } \\
\hline \multirow{3}{*}{ Left-handed } & Full Sample: & & Men: & & Women: & \\
\hline & -0.005 & 0.009 & 0.029 & 0.030 & -0.019 & -0.005 \\
\hline & $(0.020)$ & $(0.020)$ & $(0.025)$ & $(0.026)$ & $(0.031)$ & $(0.030)$ \\
\hline $\mathrm{N}$ & 3693 & 3693 & 1621 & 1621 & 2072 & 2072 \\
\hline Mean & 0.195 & 0.195 & 0.122 & 0.122 & 0.253 & 0.253 \\
\hline SD & 0.396 & 0.396 & 0.327 & 0.327 & 0.435 & 0.435 \\
\hline
\end{tabular}

Membership in humanitarian organisations

\begin{tabular}{|c|c|c|c|c|c|c|}
\hline \multirow{3}{*}{ Left-handed } & \multicolumn{2}{|l|}{ Full Sample: } & \multicolumn{2}{|l|}{ Men: } & \multicolumn{2}{|l|}{ Women: } \\
\hline & $-0.018^{*}$ & -0.014 & -0.012 & -0.011 & -0.022 & -0.017 \\
\hline & $(0.009)$ & $(0.009)$ & $(0.012)$ & $(0.012)$ & $(0.014)$ & $(0.014)$ \\
\hline $\mathrm{N}$ & 3691 & 3691 & 1619 & 1619 & 2072 & 2072 \\
\hline Mean & 0.049 & 0.049 & 0.038 & 0.038 & 0.057 & 0.057 \\
\hline \multirow[t]{3}{*}{ SD } & 0.215 & 0.215 & 0.190 & 0.190 & 0.233 & 0.233 \\
\hline & \multicolumn{6}{|c|}{ Membership in environmental organisations } \\
\hline & Full Sample: & & Men: & & Women: & \\
\hline \multirow[t]{2}{*}{ Left-handed } & 0.013 & 0.021 & -0.003 & 0.002 & 0.032 & $0.041 *$ \\
\hline & $(0.015)$ & $(0.015)$ & $(0.020)$ & $(0.019)$ & $(0.024)$ & $(0.023)$ \\
\hline $\mathrm{N}$ & 3686 & 3686 & 1618 & 1618 & 2068 & 2068 \\
\hline Mean & 0.088 & 0.088 & 0.081 & 0.081 & 0.094 & 0.094 \\
\hline SD & 0.284 & 0.284 & 0.273 & 0.273 & 0.292 & 0.292 \\
\hline Controls & no & yes & no & yes & no & yes \\
\hline
\end{tabular}

Robust standard errors in parentheses; *** $\mathrm{p}<0.01, * * \mathrm{p}<0.05, * \mathrm{p}<0.1$

Controls consist of age, gender, income and education 
Table 7: Handedness and altruistic behaviour (NLSY 97)

\begin{tabular}{|c|c|c|c|c|c|c|}
\hline & (1) & (2) & (3) & (4) & (5) & (6) \\
\hline & \multicolumn{6}{|c|}{ Donating money } \\
\hline & Full Sample: & & Men: & & Women: & \\
\hline \multirow[t]{2}{*}{ Left-handed } & -0.0228 & -0.0138 & 0.00647 & 0.00735 & $-0.0470 * *$ & $-0.0401 *$ \\
\hline & $(0.0141)$ & $(0.0138)$ & $(0.0182)$ & $(0.0180)$ & $(0.0219)$ & $(0.0215)$ \\
\hline $\mathrm{N}$ & 7673 & 7673 & 3862 & 3862 & 3811 & 3811 \\
\hline Mean & 0.218 & 0.218 & 0.179 & 0.179 & 0.258 & 0.258 \\
\hline \multirow[t]{3}{*}{ SD } & 0.413 & 0.413 & 0.383 & 0.383 & 0.438 & 0.438 \\
\hline & \multicolumn{6}{|c|}{ Volunteering } \\
\hline & Full Sample: & & Men: & & Women: & \\
\hline \multirow[t]{2}{*}{ Left-handed } & $-0.0365 * *$ & $-0.0309 * *$ & -0.0307 & -0.0294 & -0.0368 & -0.0296 \\
\hline & $(0.0147)$ & $(0.0145)$ & (0.0192) & $(0.0189)$ & $(0.0228)$ & $(0.0223)$ \\
\hline $\mathrm{N}$ & 7673 & 7673 & 3862 & 3862 & 3811 & 3811 \\
\hline Mean & 0.256 & 0.256 & 0.234 & 0.234 & 0.279 & 0.279 \\
\hline SD & 0.437 & 0.437 & 0.423 & 0.423 & 0.449 & 0.449 \\
\hline Controls & no & yes & no & yes & no & yes \\
\hline
\end{tabular}

Robust standard errors in parentheses; *** $\mathrm{p}<0.01, * * \mathrm{p}<0.05, * \mathrm{p}<0.1$

Controls consist of age, gender, income and race

likely to volunteer although the effect is only significant for the sample as a whole. Here the NLSY sample differs somewhat from the LISS sample where the negative effect of left-handedness was only observed for the male sub-sample.

Donations are arguably the closest equivalent to the dictator game in as far as the final recipient usually does not know the identity of the donor and has no opportunity to reciprocate. The donation regressions therefore confirm the external validity of our lab results as they replicate the pattern found in the lab for the dictator game both with the LISS data and the NLSY data: left-handed women are significantly less likely to donate while there is no significant difference for men. The survey data results nevertheless also confirm that one needs to be cautious when generalising lab results on social preferences to predict pro-social behaviour in general. Volunteering is a very different activity from donating money as it is much more visible and requires more personal involvement, but it is still important to note that the lab results from the dictator and public good games do not indicate the negative correlation between left-handedness and volunteering for males. ${ }^{19}$ This finding illustrates that contextual factors which are eliminated in the lab can indeed lead to different effects in the field. The same is true for membership in charitable organisations where left-handedness is (weakly)

\footnotetext{
${ }^{19}$ The reciprocity analysis based on the trust game data indicates on the other hand that absent a motive for positive reciprocity, left-handed men are less generous than right-handers.
} 
associated with lower membership in humanitarian organisations as expected, but also (weakly) with higher membership in environmental organisations amongst women.

\subsection{Survey measures of trust and reciprocity}

Our laboratory results indicate that handedness has a strong effect on giving in situations where responders can reciprocate, as well as on reciprocity itself, and that this effect is present in men but not in women. We hypothesised that the higher giving rates for left-handed males could be due to a stronger belief in the reciprocity of others, which in the case of positive reciprocity leads to higher levels of trust. It is hard to see what exactly would constitute a behavioural survey measure of these beliefs, but the "European Social Survey" module of the LISS panel contains three attitude questions which cover different aspects of the respondent's beliefs about other people's reciprocity and trustworthiness, namely whether the respondent believes that others are fair, whether others can be trusted, and whether others deserve to be trusted. These questions are "Do you think that most people would try to take advantage of you if they got the chance, or would they try to be fair?" (Fairness); "Generally speaking, would you say that most people can be trusted, or that you can't be too careful in dealing with people?" (Trustworthiness); and "Would you say that most people deserve your trust or that only very few deserve your trust?" (Trust-deserving). Respondents can answer each question on a scale from 0 to 10 whereby a higher number represents more trust. ${ }^{20}$

The Fairness and Trustworthiness questions have been used in many previous studies on trust and have been linked to choices in social preference games in the lab. ${ }^{21}$ Glaeser et al. (2000) link them to behaviour in the trust game and find that while the answers to these survey questions do not predict amounts sent, they are positively and significantly related to the proportion returned. ${ }^{22}$ Holm and Danielson (2005) find that they predict both giving and reciprocating for Swedish but not for Tanzanian subjects and Gächter et al. (2004) show that "Fairness" is significantly and positively correlated to contributions in a one-shot public good game. ${ }^{23}$ Fehr (2009) reviews the trust literature and concludes that answers to trust related survey questions are driven by similar preferences and beliefs as decisions in the trust game.

Table 8 regresses the answers to these attitude questions on a left-handedness dummy and the usual controls. $^{24}$ We can see that left-handed men, but not left-handed women, are indeed more likely

\footnotetext{
${ }^{20}$ For Fairness, 0 represents "Most people would try to take advantage of me" and 10 represents "Most people would try to be fair"; for Trustworthiness 0 represents "You can't be too careful" and 10 represents "Most people can be trusted"; and for Trust-deserving 0 represents "Very few people deserve my trust" while 10 represents "Most people deserve my trust".

${ }^{21}$ They have originally been taken from the American General Social Survey (GSS) which has used them to measure trust since 1972 .

${ }^{22}$ On the other hand, whether people agree with the statement "you can't trust strangers anymore" did significantly predict trust game offers.

23"Trustworthiness" is also positively associated with contributions but this correlation is not significant.

${ }^{24}$ We use simple OLS in these regressions. Using ordered Probit does not change any of the results.
} 
Table 8: Handedness and attitudes towards reciprocity
(1)
(2)
(3)
(4)
(5)
(6)
Fairness

\begin{tabular}{|c|c|c|c|c|c|c|}
\hline & Full Sample: & & Men: & & Women: & \\
\hline \multirow[t]{2}{*}{ Left-handed } & 0.142 & 0.224 & $0.407 *$ & $0.480 * *$ & -0.066 & -0.005 \\
\hline & $(0.142)$ & $(0.142)$ & $(0.227)$ & $(0.225)$ & $(0.176)$ & $(0.173)$ \\
\hline $\mathrm{N}$ & 1357 & 1357 & 586 & 586 & 771 & 771 \\
\hline Mean & 6.158 & 6.158 & 5.986 & 5.986 & 6.288 & 6.288 \\
\hline \multirow[t]{2}{*}{$\mathrm{SD}$} & 1.774 & 1.774 & 1.864 & 1.864 & 1.692 & 1.692 \\
\hline & \multicolumn{6}{|c|}{ Trustworthiness } \\
\hline \multirow[t]{2}{*}{ Left-handed } & 0.132 & 0.215 & $0.492 *$ & $0.598 * *$ & -0.188 & -0.110 \\
\hline & $(0.184)$ & $(0.181)$ & $(0.268)$ & $(0.274)$ & $(0.251)$ & $(0.234)$ \\
\hline $\mathrm{N}$ & 1357 & 1357 & 586 & 586 & 771 & 771 \\
\hline Mean & 5.841 & 5.841 & 5.775 & 5.775 & 5.891 & 5.891 \\
\hline \multirow[t]{2}{*}{$\mathrm{SD}$} & 2.168 & 2.168 & 2.223 & 2.223 & 2.126 & 2.126 \\
\hline & \multicolumn{6}{|c|}{ Trust-deserving } \\
\hline \multirow[t]{2}{*}{ Left-handed } & 0.052 & 0.113 & $0.409^{*}$ & $0.486 * *$ & -0.257 & -0.203 \\
\hline & $(0.152)$ & $(0.150)$ & $(0.243)$ & $(0.237)$ & $(0.183)$ & $(0.179)$ \\
\hline $\mathrm{N}$ & 1357 & 1357 & 586 & 586 & 771 & 771 \\
\hline Mean & 6.525 & 6.525 & 6.422 & 6.422 & 6.603 & 6.603 \\
\hline $\mathrm{SD}$ & 1.794 & 1.794 & 1.898 & 1.898 & 1.709 & 1.709 \\
\hline Controls & no & yes & no & yes & no & yes \\
\hline
\end{tabular}

Robust standard errors in parentheses; $* * * \mathrm{p}<0.01$, ** $\mathrm{p}<0.05, * \mathrm{p}<0.1$

Controls consist of age, gender, income and education 
to expect others to be fair, to think that most people can be trusted, and to find that most people are deserving of their trust. These results strengthen the previous interpretation of our lab results on the giving behaviour of male left-handers: they give more in the trust game because they expect others to reward their trust and not out of a desire to act altruistically. If one is willing to stretch this interpretation to the negative domain, it might also explain the ultimatum game findings, as individuals who have a stronger belief in the reciprocity of others should be more likely to reckon with the possibility of a rejection and therefore increase their offer.

\section{Conclusions}

This paper contributes to our knowledge about the determinants of individual differences in social preferences. People differ strongly from each other in their degrees of altruism, trust, fairness, and reciprocity and the fact that these strong differences occur even in the tightly controlled environment of lab experiments suggests that, rather than determined on the spot by circumstantial factors alone, they may be determined by deep-seated differences in preferences. What determines these preferences is so far largely unexplored.

We present evidence from a controlled laboratory experiment and two large online surveys showing that handedness is a significant predictor of individual levels of altruism and reciprocity. Handedness is a well-documented predictor of neural differences and our results consequently strongly hint at a biological basis for social preferences.

Our lab results show that left-handed men make choices that are markedly different from those of right-handed men when the affected individuals have a chance to reciprocate. They are also themselves more likely to exhibit positive reciprocity. These effects are not present in left-handed women who, on the other hand, are much less altruistic in the dictator game where reciprocity does not play a role. A plausible explanation for the behaviour of male left-handers is that they have a stronger belief in the trustworthiness and reciprocity of others. This would mean that they give more not out of a desire to make the responder better off but because they believe, in the case of the trust game, that their trust will be rewarded and, in the case of the ultimatum game, that low offers would be rejected. Connecting our lab results to large-scale survey data, we can demonstrate the external validity of our findings to a degree which is usually difficult to accomplish for laboratory studies. We do this along two dimensions: firstly, we can show that our experimental results apply to a diverse and representative non-student sample and secondly, we can show that they translate to behaviour outside the lab. We use both Dutch data from the LISS panel and US data from the NLSY and can therefore confirm that our results remain valid not only across samples but also across continents.

We find that the lab finding of lower altruism in left-handers translates to lower rates of charitable giving, lower willingness to do volunteer work, and lower rates of membership in humanitarian orga- 
nisations. Especially for donations, arguably the closest equivalent of the dictator game, the observed pattern in both the Dutch and the US data are consistent with the patterns found in the lab. We also use a series of attitude questions which gauge the respondent's beliefs about others' fairness and trustworthiness to show that left-handed men, but not women, are indeed more likely to think that others are trustworthy and fair, confirming our lab results. But it needs to be noted that we also observe gender differences for some of the survey measures of altruism which do not correspond to those found in the lab. We therefore conclude that one nevertheless needs to be careful when generalising lab experiment results on social preferences to predict pro-social behaviour in general.

Left-handedness, particularly in men, is associated with a stronger integration of the two hemispheres of the brain and therefore brain functions. A tentative explanation for our findings is that these differences in neural structures lead to differences in reciprocity and beliefs about other people's reciprocity, potentially because (male) left-handers find it easier to process and take into account information about others and reckon with their possible intentions. More specifically, our results indicate that brain lateralisation and the size of the corpus callosum play an important role in shaping social preferences. In summary, our contribution is twofold. Firstly, we show that neural differences associated with handedness lead to strikingly different choices in social preference games in the laboratory. The observed differences are particularly strong for reciprocal behaviour which is inextricably linked to our expectations and beliefs concerning the behaviour and motivations of others. Secondly, we show that these findings equally apply to a diverse non-student population and partly carry over to the field where we observe strong effects on the prevalence of altruistic behaviour both in the Netherlands and the US. We conclude that social preferences are at least partially innate. 


\section{References}

Ashraf, Nava, Iris Bohnet, and Nikita Piankov, "Decomposing trust and trustworthiness," Experimental Economics, 2006, 9, 193-208.

Baron-Cohen, Simon, The Essential Difference, Penguin, 2003.

_, Svetlana Lutchmaya, and Rebecca Knickmeyer, Prenatal testosterone in mind, MIT Press, 2004.

Baumgartner, Thomas, Markus Heinrichs, Aline Vonlanthen, Urs Fischbacher, and Ernst Fehr, “Oxytocin Shapes the Neural Circuitry of Trust and Trust Adaptation in Humans.," Neuron, 2008, 58 (4), 639-650.

Berg, Joyce, John Dickhaut, and Kevin McCabe, “Trust, Reciprocity, and Social History," Games and Economic Behavior, 1995, 10 (1), 122-142.

Buchan, Nancy R., Rachel T. A. Croson, and Robyn M. Dawes, "Swift Neighbors and Persistent Strangers: A Cross-Cultural Investigation of Trust and Reciprocity in Social Exchange," The American Journal of Sociology, 2002, 108 (1), 168-206.

Burnham, Terence C., "High-testosterone men reject low ultimatum game offers.," Proceedings of the Royal Society, 2007, 274, 2327-2330.

Cesarini, David, Christopher T. Dawes, James H. Fowler, Magnus Johannesson, Paul Lichtenstein, and Björn Wallace, "Heritability of cooperative behavior in the trust game," Proceedings of the National Academy of Sciences, 2008, 105 (10), 3721-3726.

_, _, Magnus Johannesson, Paul Lichtenstein, and Björn Wallace, "Genetic Variation in Preferences for Giving and Risk Taking," Quarterly Journal of Economics, 2009, 124 (2), 809-842.

Coren, Stanley, The left-hander syndrome, the causes and consequences of left-handedness, New York: Vintage, 1993.

_ , "Differences in Divergent Thinking as a Function of Handedness and Sex," The American Journal of Psychology, 1995, 108 (3), 311-325.

Croson, Rachel and Uri Gneezy, "Gender differences in preferences," Journal of Economic Literature, 2009, 47 (2), 448-74.

Denny, Kevin and Vincent O'Sullivan, “The Economic Consequences of Being Left-Handed: Some Sinister Results," Journal of Human Resources, 2007, XLII (2), 353-374. 
Faurie, Charlotte, Nicolas Vianey-Liaud, and Michel Raymond, "Do left-handed children have advantages regarding school performance and leadership skills?," Laterality, 2006, 11 (1), 57-70.

Fehr, Ernst, "On The Economics and Biology of Trust," Journal of the European Economic Association, 2009, 7 (2-3), 235-266.

Fischbacher, Urs, “z-Tree: Zurich toolbox for ready-made economic experiments," Experimental Economics, 2007, 10 (2), 171-178.

Gächter, Simon, Benedikt Herrmann, and Christian Thöni, "Trust, voluntary cooperation, and socio-economic background: survey and experimental evidence," Journal of Economic Behavior \& Organization, 2004, 55 (4), $505-531$.

_, , and _ , "Culture and cooperation," Philosophical Transactions of the Royal Society B: Biological Sciences, 2010, 365 (1553), 2651-2661.

Geschwind, Norman and Albert S. Galaburda, Cerebral lateralisation, MIT Press, 1987.

Glaeser, Edward L., David I. Laibson, José A. Scheinkman, and Christine L. Soutter, "Measuring Trust," Quarterly Journal of Economics, 2000, 115 (3), 811-846.

Goldberg, Elkhonon, Richard Harner, Mark Lovell, Kenneth Podell, and Silvma Riggio, "Cognitive Bias, Functional Cortical Geometry, and the Frontal Lobes: Laterality, Sex, and Handedness," Journal of Cognitive Neuroscience, 1994, 6 (3), 276-296.

Grimshaw, Gina, M. Philip Bryden, and Jo-Anne Finegan, "Relations between prenatal testosterone and cerebral lateralization in children," Neuropsychology, 1995, 9 (1), 68 - 79.

Güth, Werner, Rolf Schmittberger, and Bernd Schwarze, "An experimental analysis of ultimatum bargaining," Journal of Economic Behavior \& Organization, 1982, 3 (4), 367-388.

Henrich, Joseph, Robert Boyd, Samuel Bowles, Colin Camerer, Ernst Fehr, Herbert Gintis, and Richard McElreath, "In Search of Homo Economicus: Behavioral Experiments in 15 Small-Scale Societies," The American Economic Review, 2001, 91 (2), 73-78.

Herrmann, Benedikt, Christian Thöni, and Simon Gächter, "Antisocial Punishment Across Societies," Science, 2008, 319 (5868), 1362-1367.

Hines, Melissa, Lee Chiu, Lou Ann McAdams, Peter Bentler, and Jim Lipcamon, "Cognition and the Corpus Callosum: Verbal Fluency, Visuospatial Ability, and Language Lateralization Related to Midsagittal Surface Areas of Callosal Subregions," Behavioral Neuroscience, 1992, 106 (1), 3 14. 
Holm, H. J. and A. Danielson, "Tropic Trust Versus Nordic Trust: Experimental Evidence From Tanzania And Sweden,” The Economic Journal, 2005, 115 (503), 505-532.

Israel, Salomon, Elad Lerer, Idan Shalev, Florina Uzefovsky, Mathias Riebold, Efrat Laiba, Rachel Bachner-Melman, Anat Maril, Gary Bornstein, Ariel Knafo, and Richard P. Ebstein, "The Oxytocin Receptor (OXTR) Contributes to Prosocial Fund Allocations in the Dictator Game and the Social Value Orientations Task," PLoS ONE, 05 2009, 4, e5535.

Johnston, David W., Manisha Shah, and Michael A. Shields, "Handedness, Time Use and Early Childhood Development," IZA Discussion Papers 4300, Institute for the Study of Labor (IZA) 2007.

Kahneman, Daniel, Jack L. Knetsch, and Richard H. Thaler, "Fairness and the Assumptions of Economics," The Journal of Business, 1986, 59 (4), S285-S300.

Knafo, Ariel, S. Israel, A. Darvasi, R. Bachner-Melman, F. Uzefovsky, L. Cohen, E. Feldman, E. Lerer, E. Laiba, Y. Raz, L. Nemanov, I. Gritsenko, C. Dina, G. Agam, B. Dean, G. Bornstein, and R. P. Ebstein, "Individual differences in allocation of funds in the dictator game associated with length of the arginine vasopressin 1a receptor RS3 promoter region and correlation between RS3 length and hippocampal mRNA," Genes, Brain and Behavior, 2008, 7 (3), 266-275.

Knecht, S., M. Deppe, B. Drager, L. Bobe, H. Lohmann, E.-B. Ringelstein, and H. Henningsen, "Language lateralization in healthy right-handers," Brain, 2000, 123 (1), 74-81.

Kosfeld, Michael, Markus Heinrichs, Paul J. Zak, Urs Fischbacher, and Ernst Fehr, "Oxytocin increases trust in humans.," Nature, 2005, 435 (2), 673-676.

Ledyard, John, "Public Goods: A Survey of Experimental Research," in J. H. Kagel and Alvin E. Roth, eds., The Handbook of Experimental Economics, Princeton, NJ: Princeton University Press, 1995.

Levitt, Steven D. and John A. List, "What Do Laboratory Experiments Measuring Social Preferences Reveal about the Real World?," The Journal of Economic Perspectives, 2007, 21 (2), 153174.

Manning, John T. and M. Peters, "Digit ratio (2D:4D) and hand preference for writing in the BBC Internet Study," Laterality: Asymmetries of Body, Brain and Cognition, 2009, 14 (5), 528-540.

_, Simon Baron-Cohen, Sally Wheelwright, and S. Sanders, "The 2nd to 4th digit ratio and autism," Developmental Medicine \& Child Neurology, 2001, 43 (3), 160-164.

Millet, Kobe and Siegfried Dewitte, "Second to fourth digit ratio and cooperative behavior," Biological Psychology, 2006, 71 (1), 111 - 115. 
_ and _, "The presence of aggression cues inverts the relation between digit ratio (2D:4D) and prosocial behaviour in a dictator game," British Journal of Psychology, 2009, 100, 151 - 162.

Oosterbeek, Hessel, Randolph Sloof, and Gijs van de Kuilen, "Cultural Differences in Ultimatum Game Experiments: Evidence from a Meta-Analysis," Experimental Economics, 2004, 7 (2), 171188.

Roth, Alvin E., "Bargaining Experiments," in J. H. Kagel and Alvin E. Roth, eds., The Handbook of Experimental Economics, Princeton, NJ: Princeton University Press, 1995.

_, Vesna Prasnikar, Masahiro Okuno-Fujiwara, and Shmuel Zamir, "Bargaining and Market Behavior in Jerusalem, Ljubljana, Pittsburgh, and Tokyo: An Experimental Study," The American Economic Review, 1991, 81 (5), 1068-1095.

Ruebeck, Christopher S., Joseph E. Harrington, and Robert Moffitt, "Handedness and earnings," Laterality: Asymmetries of Body, Brain and Cognition, 2007, 12 (2), 101-120.

Sanders, Barry, James R. Wilson, and S. G. Vandenberg, "Handedness and Spatial Ability," Cortex, 1982, 18 (1), 79-90.

van den Bergh, Bram and Siegfried Dewitte, "Digit ratio (2D:4D) moderates the impact of sexual cues on men's decisions in ultimatum games," Proceedings of the Royal Society B: Biological Sciences, 2006, 273 (1597), 2091-2095.

Wallace, Björn, David Cesarini, Paul Lichtenstein, and Magnus Johannesson, "Heritability of ultimatum game responder behavior," Proceedings of the National Academy of Sciences, 2007, 104 (40), 15631-15634.

Witelson, Sandra F., "The Brain Connection: The Corpus Callosum is Larger in Left-Handers," Science, 1985, 229 (4714), 665-668.

_ , "Neural sexual mosaicism: Sexual differentiation of the human temporo-parietal region for functional asymmetry," Psychoneuroendocrinology, 1991, 16 (1-3), 131 - 153.

- and Charles H. Goldsmith, "The relationship of hand preference to anatomy of the corpus callosum in men," Brain Research, 1991, 545 (1-2), 175 - 182.

_ and Richard S. Nowakowski, "Left out axoms make men right: A hypothesis for the origin of handedness and functional asymmetry," Neuropsychologia, 1991, 29 (4), 327 - 333.

Zak, Paul J., Angela A. Stanton, and Sheila Ahmadi, “Oxytocin Increases Generosity in Humans.," PLoS One, 2007, 2. 
_ , Robert Kurzban, Sheila Ahmadi, Ronald S. Swerdloff, Jang Park, Levan Efremidze, Karen Redwine, Karla Morgan, and William Matzner, "Testosterone Administration Decreases Generosity in the Ultimatum Game.," PLoS One, 2009, 4.

Zethraeus, Niklas, Ljiljana Kocoska-Maras, Tore Ellingsen, Bo von Schoultz, Angelica Linden Hirschberg, and Magnus Johannesson, "A randomized trial of the effect of estrogen and testosterone on economic behavior," PNAS, 2009, 106, 6535-6538. 